\title{
Prevalence and Correlates of HIV Infection Among Men Who Have Sex with Men in Congo, 2017
}

\author{
Gilbert Ndziessi $^{1,}$,, Axel Julius Aloumba ${ }^{2}$, Raphael Bioko ${ }^{1}$, Benjamin Atipo ${ }^{3}$, Joseph Axel Ngatsie ${ }^{1}$, \\ Michel Bitemo ${ }^{3}$, Gontran Ondzotto ${ }^{1}$
}

${ }^{1}$ Faculty of Health Sciences, Marien Ngouabi University, Brazzaville, Congo

${ }^{2}$ Infectious Diseases Unit, University Hospital Centre, Brazzaville, Congo

${ }^{3}$ National Council for the Fight against AIDS and Epidemics, Minister of health and Population, Brazzaville, Congo

\section{Email address:}

ndziessi@yahoo.fr (G. Ndziessi), axel.aloumba@gmail.com (A. J. Aloumba), rabio-ngolo@hotmail.fr (R. Bioko), atipobenjamin65@gmail.com (B. Atipo),josaxel@yahoo.fr (J. A. Ngatsie), michelbitemo@gmail.com (M. Bitemo), gontranondzotto@gmail.com (G. Ondzotto)

${ }^{*}$ Corresponding author

\section{To cite this article:}

Gilbert Ndziessi, Axel Julius Aloumba, Raphael Bioko, Benjamin Atipo, Joseph Axel Ngatsie, Michel Bitemo, Gontran Ondzotto. Prevalence and Correlates of HIV Infection Among Men Who Have Sex with Men in Congo, 2017. International Journal of HIV/AIDS Prevention, Education and Behavioural Science. Vol. 6, No. 2, 2020, pp. 67-72. doi: 10.11648/j.ijhpebs.20200602.16

Received: November 16, 2020; Accepted: November 30, 2020; Published: December 8, 2020

\begin{abstract}
Background: The risk of contracting HIV is very high in Men who have sex with men (MSM) compared to the general population. This study aimed to estimates HIV prevalence among MSM in 2018 in Congo and identified associated factors. Methods: Cross-sectional study using the respondent-driven sampling method was conducted. Blood samples were collected and tested for HIV. Chi-square or Fischer test was used for proportion comparisons and logistic regression was carried out to assess predictors of HIV infection in MSM using the Statistical Package for the Social Sciences (SPSS) software. Results: HIV prevalence among $182 \mathrm{MSM}$ was $41,2 \%$. Average age was $25 \pm 5$ years. Current age between 25-29 years (ORa=18.9 [1.925.0]; $\mathrm{p}=0.01)$, current age between 30-34 years $(\mathrm{ORa}=47$ [40.0 - 59.0]; $\mathrm{p}=0.003)$, not use condoms for passive penetration $(\mathrm{ORa}=5.2[1.1-24.1] ; \mathrm{p}=0.03)$, and non-use of the condom due to faithfulness to one's partner $(\mathrm{ORa}=6.9[1.9-25.1] ; \mathrm{p}=0.003)$ were found associated with HIV infection among MSM. Conversely, being more than 20 years old at first anal sex was found to be associated with reduced risk of acquiring $\mathrm{HIV}(\mathrm{ORa}=0.2 ; \mathrm{IC}=1.1-11,4 ; \mathrm{p}=0.03)$. Conclusion: Among MSM in Congo, HIV prevalence is high as a result of high-risk sexual behavior. Programs aimed at reducing risk should be enhanced in MSM including, as a priority, preventive advice, condom supplies, HIV and STI testing and communication.
\end{abstract}

Keywords: HIV, Prevalence, Men Who Have Sex with Men, Risk Factors, Congo

\section{Introduction}

The HIV epidemic has affected people around the world. By 2019, 38 million people worldwide were living with HIV, 1.7 million people were newly infected and 690,000 died from AIDS-related diseases. Africa continues to be the region of the world with the most cases, new infections and deaths [1]. According to the Common United Nations Programme on HIV/AIDS (UNAIDS), men who have sex with men (MSM), sex workers, transsexuals, injecting drug users and prisoners and other incarcerated persons are the top five groups of people particularly vulnerable to HIV and accounted with their partners for $80 \%$ of new HIV infections worldwide (outside sub-Saharan Africa) in 2016 [2]. Sex between men has long been considered non-existent in Africa. Currently, the subject remains taboo and sex between men is criminalized by law in many countries [3, 4]. Indeed, factors such as government denial, stigmatization and ignorance or lack of adequate information often lead to neglect of this MSM population $[3,5]$. All this factor impacts on behaviour change as it limits the possibility of using certain safer HIV prevention practices such as condom use, testing for HIV and access to healthcare services [6], which contributes to developing and maintaining the HIV epidemic. Subsequently, HIV surveys of MSM in Africa revealed high HIV prevalence, estimated in many countries between $12 \%$ and $43 \%[7,8]$ and 
key factors associated with HIV-positive status in MSM included low levels of education, unprotected anal sex, rape, verbal and physical abuse, and versatility $[9,10]$.

In Congo, the HIV epidemic is both generalized and concentrated, with global prevalence of $3.2 \%$, based on the results of the Seroprevalence and AIDS Indicators Survey 2009 [11] and 26,1\% among MSM from behavioural and serological survey on HIV conducted in 2012 [12]. Despite the high prevalence of HIV, to our knowledge, the factors associated with HIV among MSM in Congo are not documented. This study aimed to estimates HIV prevalence among MSM in Congo in 2018 and identified associated factors.

\section{Patients and Methods}

\subsection{Study Design}

The data used for this study are from the integrated bio-behavioural monitoring survey (IBBS) conducted in Congo in 2018. Briefly, IBBS is a cross sectional national survey carried out among most hard-to-reach populations including 700 sex workers, 223 MSM and 206 Prisoners.

A sample of $182 \mathrm{MSM}$ was selected using respondent-led sampling (RDS). A full description of this sampling method for difficult-to-reach populations is provided elsewhere [13, 14]. Data was collected using android tablets previously configurated, exported from CSEntry databases to Excel and SPSS for storage. IBBS database contains information on MSM including socio-demographic characteristics (i.e., age, marital status, place of residence, religion, level of education, relationship with peer recruiter, socio-cultural origin and nationality), sexual knowledge (behaviors or practices, opinions and attitudes towards STIs and HIV/AIDS) and on sexual life (type and number of sexual partners, sexual practices). Interviews were conducted by MSM peers and were conducted in a secure environment to ensure the confidentiality. After receiving comprehensive information in understandable terms and according to the study objectives, each MSM participant signed a consent form to confirm participation in the study. The study protocol was approved by the National Ethics Committee and the Institutional Task Force of the Ministry of Health.

\subsection{HIV Testing Procedures}

Samples were collected at the survey sites by trained health workers previously upgraded. Blood samples taken by venous route (elbow fold) were collected in the appropriate tubes and quality control was subsequently carried out at the national laboratory of public health (LNSP) in Brazzaville. For all respondents, pre-test counselling was provided prior to blood collection. The rapid on-site screening was carried out in accordance with WHO/UNAIDS Strategy II by the use of sensitive first-line testing [15]: Determines HIV1\&2®, then samples positive tests were subjected to the second discriminatory test, Bioline HIV1\&2®. Confirmation of HIV test results and quality control were done at National Public
Health Laboratory (NPSL), for all samples, in accordance with the HIV screening algorithm used in the country. To this end, the following tests were performed on each blood sample: 1st test (ELISA GENSCREEN ULTRA HIV AG-AC); 2nd test (MULTIPORT HIV1/2); PCR test for the quantification of HIV viral RNA in case of discrepancy between test.

\subsection{Variables Analyzed}

HIV infection was the dependent variable used in analysis and was classified as dichotomic (Yes/No). The independent variables used in this analysis were: Age, Education level, Marital status, employment status, Age at first sex with another man, Number of active anal intercourse with men, unprotected anal sex between men and condom use.

\subsection{Analysis}

Proportions were calculated for each variable. Proportion of $\mathrm{HIV}+\mathrm{MSM}$ was compared between the different modalities of explicative variables, using Chi-square or Fischer test. Logistic regression was carried out to assess predictors of HIV infection in MSM using the Statistical Package for the Social Sciences (SPSS) software version 17.0. We performed in first bivariate analyses in which each explanatory variable was crossed with the response variable and odds ratios (OR) with their $95 \%$ confidence intervals were calculated to estimate the association strength of each of the explanatory variables with the response variable. In second time, multivariate analysis was performed but only variables that had a $p \leq 0.20$ at the time of the bivariate analysis were eligible. The top-down step-by-step method was used. To do this, only the variables that were in the final model are presented in the results. The procedure to eliminate non-significant variables $(\mathrm{P}>0.05)$ from the model was based on the maximum likelihood ratio with a first-order alpha error risk of $5 \%$.

\section{Results}

A total of four seeds were selected from MSM in both cities selected for the study, namely Brazzaville and Pointe Noire. The social network sizes of MSM seeds ranged from 6 (Brazzaville) to 98 (Pointe-Noire). Age of MSM seeds varies from 24 to 39 years old. All seeds reported a single marital status. Three of the seeds were bisexuals. Of the four seeds in the study, only seed one from Brazzaville has a higher education level; the other three had secondary education. The total number of recruits per seed varies from 48 to 64 . In general, all seeds reached at least the fourth round of recruitment. The synoptic view of the recruitment chains from the four seeds is shown in Figure 1. Of a total of 223 MSM recruited in which 52.9\% in Brazzaville and $47.1 \%$ in Pointe Noire, 41 declined screening for HIV and 182 accepted testing for HIV. Participants' mean age was $25 \pm 5$ years, $62 \%$ had level education do not exceed the grammar school, $41 \%$ were unemployed and $72 \%$ reported a single marital status (Table 1). Sixty percent $(60 \%)$ self-identified as bisexual and $40 \%$ reported gay or homosexual identity. Regarding sexual 
behaviours, $43 \%$ reported having more than 30 anal sex with others men in the last six months before the study, $67.6 \%$ reported having non-condom receptive anal intercourse. (Table 2). Concerning the sexual role during having sex, $44 \%$ declared to be versatile, $35 \%$ insertive and $21 \%$ receptive.

The HIV prevalence was $41.2 \%$ [34.2\%-48.6\%], with no significant difference between departments of Brazzaville and Pointe Noire, $35.2 \%$ versus $46.8 \%(p=0,113)$ respectively. As shown in Table 1, there was no significant difference between HIV-positive MSM and HIV-negative MSM in terms of socio-demographic characteristics (level of education, marital status and employment status) with the exception of age $(\mathrm{p}=0.018)$. It was similar concerning sexual practices with the exception of the age at first sex with another man $(\mathrm{p}=0.027)$ as shown in Table 2 .

In multivariate analysis, current age from 25 to 29 years (0R $[95 \% \mathrm{CI}]=18[13-25] ; \mathrm{p}=0.003)$, current age from 30 to 34 years $(0 \mathrm{R}[95 \% \mathrm{CI}]=44[41-59] ; \mathrm{p}=0.003)$, non- condom in last receptive anal sex with main or casual partner (0R $[95 \%$ $\mathrm{CI}]=5.2[1.1-24.1] ; \mathrm{p}=0.037)$ and not using condoms because of faithfulness to one's partner $(0 \mathrm{R}[95 \% \mathrm{CI}]=6.9[1.9-25.1]$; $\mathrm{p}=0.003$ ) were significantly associated with HIV infection among MSM (Table 3).

\section{Discussion}

Key populations like MSM should be targeted by AIDS programs to help control the epidemic in the country. Our study was conducted from this perspective and enabled us to identify the sociodemographic and behavioural characteristics of MSM, measure HIV prevalence among MSM in 2018, and identify factors associated with positive HIV status. This study is the second IBBS (Integrated Bio-Behavioural Surveillance) survey of MSM in the Congo, the first having been conducted in 2017. Our results show that the MSM population in Congo is very young, with 96 out of 100 MSM under the age of 30, most of them not living in union and more frequently bisexual, as indicated in earlier studies in the African context [8, 16-21]. Previous studies show that the high incidence of single marital status can be a protective behaviour against the stigma and physical and sexual assaults severally experienced by MSM [7].

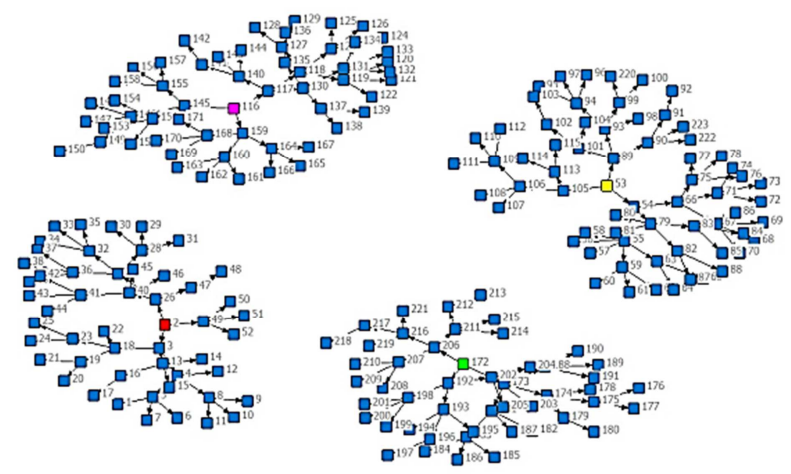

Figure 1. RDS recruitment diagram from 223 MSM recruited in Brazzaville and Pointe-Noire, Congo.

Read=seed 1 Brazzaville; Yellow=seed 2 Brazzaville; magenta=seed 1 Pointe-Noire; green=seed 2 Pointe Noire.

In addition, the high proportion of bisexual MSM observed in this study indicates that MSM population is a gateway for HIV infection in general population, i.e., a higly exposed population whose members are likely to have unprotected sex with people who would otherwise be less exposed to the virus.

Our survey revealed a high HIV prevalence (43\%) amongst MSM in 2017. In comparison to the prevalence of $32 \%$ in the previous study on IBBS in 2012 [12], there was an $11 \%$ increase between 2012 and 2017. This can be explained by the fact that most interventions of prevention and diagnostic from the national AIDS control programme were stopped for lack of funding between 2016 and 2017. However, several studies have reported similar prevalence in sub-Saharan Africa [18, 19].

Table 1. Main socio- demographic characteristics of MSM by HIV status, IBBS survey Congo 2018.

\begin{tabular}{|c|c|c|c|c|c|c|c|}
\hline & \multicolumn{2}{|c|}{ Effective } & \multicolumn{2}{|c|}{ Test VIH Positive } & \multicolumn{2}{|c|}{ Test VIH Negative } & \multirow{2}{*}{$\mathbf{P}$} \\
\hline & $\mathbf{n}$ & $\%$ & $\mathbf{n}$ & $\%$ & $\mathbf{n}$ & $\%$ & \\
\hline Age (years) & & & & & & & 0.018 \\
\hline $18-19$ & 16 & 8.8 & 3 & 4.0 & 13 & 12.1 & \\
\hline $20-24$ & 71 & 39.0 & 25 & 33.3 & 46 & 43.0 & \\
\hline $25-29$ & 58 & 31.9 & 29 & 38.7 & 29 & 27.1 & \\
\hline $30-34$ & 29 & 15.9 & 15 & 20.0 & 14 & 13.1 & \\
\hline$>35$ & 8 & 4.4 & 3 & 4.0 & 5 & 4.7 & \\
\hline Education level & & & & & & & 0.271 \\
\hline Primary/college & 44 & 24.2 & 16 & 21.3 & 28 & 26.2 & \\
\hline Grammar school & 69 & 37.9 & 27 & 36.0 & 42 & 39.3 & \\
\hline University & 29 & 15.9 & 7 & 9.3 & 22 & 20.6 & \\
\hline Unspecified & 40 & 22.0 & 25 & 33.3 & 15 & 14.0 & \\
\hline Matrimonial status & & & & & & & 0,720 \\
\hline Married & 5 & 2.7 & 1 & 1.3 & 4 & 3.7 & \\
\hline Not in union & 131 & 72.0 & 46 & 61.3 & 85 & 79.4 & \\
\hline Widowed or divorced & 1 & 0.5 & 1 & 1.3 & 0 & 0.0 & \\
\hline In free union & 5 & 2.7 & 2 & 2.7 & 3 & 2.8 & \\
\hline Unspecified & 40 & 22.0 & 25 & 33.3 & 15 & 14.0 & \\
\hline Professional status & & & & & & & 0.091 \\
\hline
\end{tabular}




\begin{tabular}{|c|c|c|c|c|c|c|c|}
\hline & \multicolumn{2}{|c|}{ Effective } & \multicolumn{2}{|c|}{ Test VIH Positive } & \multicolumn{2}{|c|}{ Test VIH Negative } & \multirow{2}{*}{$\mathbf{P}$} \\
\hline & $\mathrm{n}$ & $\%$ & $n$ & $\%$ & $\mathrm{n}$ & $\%$ & \\
\hline Unemployed & 75 & 41.2 & 23 & 30.7 & 52 & 48.6 & \\
\hline Formal sector & 18 & 9.9 & 7 & 9.3 & 11 & 10.3 & \\
\hline Informal sector & 50 & 27.5 & 21 & 28.0 & 29 & 27.1 & \\
\hline Unspecified & 39 & 21.4 & 24 & 32.0 & 15 & 14.0 & \\
\hline Department & & & & & & & 0.113 \\
\hline Brazzaville & 88 & 48.4 & 31 & 35.2 & 57 & 64.8 & \\
\hline Pointe-Noire & 94 & 51.6 & 44 & 46.8 & 50 & 53.2 & \\
\hline
\end{tabular}

During this period, funding from the Global Fund to fight AIDS, tuberculosis and malaria, the main funder of HIV program in congo, focused on patients in active queue regardless of communication and screening interventions. It is important to know that AIDS programs in Congo are highly dependent on external funding, as in most sub-Saharan Africa countries. Accordingly, the funding stop causes the cessation of activities. Our results suggest that the sources of funding for the national AIDS programme should be diversified in order to intensify and sustain HIV interventions, with a view to achieving the UNAIDS 90-90-90 targets [22].

The results of our research also showed that the earlier homosexual beginnings i.e., the early age of the first sex with another man was independently associated with HIV infection in the study population, with nearly four times the likelihood of HIV infection than the reference group. This may be explained at a young age by the vulnerability to sexual health problems due to the adoption of high-risk sexual behavior and lack of access or low usage of condoms. Likewise, repeated exposures to risk over the course of a lifetime may explain the association between HIV infection and later current age [23]. This pattern of adolescent sexual-risk behaviour has been several times reported in studies on sexual and reproductive behaviour in many countries in sub-Saharan Africa. For example, it has been shown that a teenager who had an early pregnancy or history of abortion were more likely to have at maturity to have unplanned and unintended pregnancies, compared to women without history of abortion when teenager [24, 25].

Unsurprisingly, the findings of our study show that the non-systematic condom during receptive anal sex with other men is a factor that significantly increases the risk of contracting HIV, in line with the results of earlier studies assessing HIV risk factors among MSM in African countries [26] and elsewhere [27, 28].

Table 2. Distribution of MSM by sexual practices and HIV status, IBBS survey Congo 2018.

\begin{tabular}{|c|c|c|c|c|}
\hline & Effective n (\%) & VIH positive n $(\%)$ & VIH negative n $(\%)$ & $\mathbf{P}$ \\
\hline Number of active anal intercourse with men in the last 6 months & & & & 0.25 \\
\hline$<4$ & $45(24.7)$ & $15(2.0)$ & $30(28.0)$ & \\
\hline $4-7$ & $23(12.6)$ & $9(12.0)$ & $14(13.1)$ & \\
\hline $8-30$ & $35(19.2)$ & $12(16.0)$ & $23(21.5)$ & \\
\hline$>30$ & $79(43.4)$ & $39(52.0)$ & $40(37.4)$ & \\
\hline \multicolumn{5}{|l|}{ Sexual practices at last anal intercourse with partner } \\
\hline Yes & $123(67.6)$ & $43(57.3)$ & $80(78.4)$ & \\
\hline No & $59(32.4)$ & $32(42.7)$ & $27(25.2)$ & \\
\hline Non-systematic condom during receptive anal sex with others men in the last 6 months & & & & 0.77 \\
\hline Yes & $11(6.0)$ & $5(6.7)$ & $6(5.6)$ & \\
\hline No & $171(94.0)$ & $70(93.3)$ & $101(94.4)$ & \\
\hline Anulingus with condom use & & & & 0.89 \\
\hline Yes & $96(52.7)$ & $40(53.3)$ & $56(52.3)$ & \\
\hline Age at first sex with another man (Years) & & & & 0.03 \\
\hline $10-14$ & $51(2.0)$ & $21(28.0)$ & $30(28.0)$ & \\
\hline $15-19$ & $69(37.9)$ & $25(33.3)$ & $44(41.1)$ & \\
\hline$\geq 20$ & $21(11.5)$ & $4(5.3)$ & $17(15.9)$ & \\
\hline Unspecified & $41(22.5)$ & $25(33.3)$ & $16(15.0)$ & \\
\hline \multicolumn{5}{|l|}{ Reasons for not using condoms with sexual partners } \\
\hline Faithfulness & & & & 0.67 \\
\hline Yes & $29(15.9)$ & $13(17.3)$ & $16(15.0)$ & \\
\hline No & $153(84.1)$ & $62(82.7)$ & $91(85.0)$ & \\
\hline Condom reduces sexual sensations & & & & 0.16 \\
\hline Yes & $94(51.6)$ & $10(13.3)$ & $84(78.5)$ & \\
\hline No & $88(48.4)$ & $65(86.7)$ & $23(21.5)$ & \\
\hline
\end{tabular}

Previous studies have indicated that MSM are 5 to 18 times more likely to become infected with HIV than 
heterosexuals [29]. These result that from a meta-analysis on observational studies of HIV-1 transmission risk among heterosexuals by Boily et al. in 2009 are given here for information to clarify the results of our study et al. in 2009 are given here for information to clarify the results of our study. We did not explore these comparisons in our study.
It is well-known that unprotected anal sex with penetration is an important factor for HIV transmission, especially for the passive partner, because of a high density of lymphoid nodules in the rectal mucosa which increase sensitivity to abrasions compared to the vaginal mucosa [30].

Table 3. Factors associated with HIV-positive status in men who have sex with men, IBBS survey Congo 2018 (final model of logistic regression, $N=182$ ).

\begin{tabular}{|c|c|c|c|c|c|c|}
\hline & $\mathbf{O R}^{\mathbf{b}}$ & CI (95\%) & $\mathbf{p}$ & $\mathbf{O R}_{\mathrm{A}}$ & CI (95\%) & p \\
\hline \multicolumn{7}{|l|}{ Age (years) } \\
\hline 18-19 (Ref.) & 1.0 & & & 1.0 & & \\
\hline $20-24$ & 2.4 & $0.6-9.1$ & 0.212 & 5.5 & $0.7-7.5$ & 0.142 \\
\hline $25-29$ & 4.3 & $1.1-16.8$ & 0.034 & 18.9 & $1.9-25.0$ & 0.012 \\
\hline $30-34$ & 4.6 & $1.1-19.8$ & 0.038 & 47.0 & $40.0-59.0$ & 0.003 \\
\hline$\geq 35$ & 2.6 & $0.4-17.5$ & 0.325 & 14.0 & $11.0-22.0$ & 0.063 \\
\hline \multicolumn{7}{|c|}{ Non-condom in last receptive anal sex with main or casual partner } \\
\hline No (Ref.) & 1.0 & & & 1.0 & & \\
\hline Yes & 1.2 & $0.4-4.09$ & 0.768 & 5.2 & $1.1-24.1$ & 0.037 \\
\hline \multicolumn{7}{|c|}{ Age at first sex with another man (Years) } \\
\hline 10-14 (Ref.) & 1.0 & & & 1.0 & & \\
\hline $15-19$ & 0.8 & $0.4-1.71$ & 0.582 & 0,8 & $0.4-1.8$ & 0.626 \\
\hline$>20$ & 0.3 & $0.1-1.14$ & 0.081 & 0.2 & $0.1-0.8$ & 0.019 \\
\hline \multicolumn{7}{|c|}{ Reasons for not using condoms with sexual partners } \\
\hline \multicolumn{7}{|l|}{ Faithfulness } \\
\hline Yes (Ref.) & 1.0 & & & 1.0 & & \\
\hline No & 1.2 & $0.5-2.65$ & 0.666 & 6.9 & $1.9-25.1$ & 0.003 \\
\hline
\end{tabular}

In spite of these results, some limitations of our study should be acknowledged. First, the Respondent-Driven Sampling sample used in this study can induce selection bias by the preferential referral behaviour by the seeds or network members [31]. nevertheless, the seeds have been trained on non-judgmental risk assessment approaches to control selection bias. Nevertheless, the RDS is an appropriate sampling strategy to constitute sample of a hidden population $[14,30,32]$. In addition, the declarative data are likely to lead to a social desirability bias that may over- or underestimate the associations observed in this study. However, the HIV testing was carried out using standard procedures and the statistical associations observed are the same as those reported by several studies previously cited [15].

\section{Conclusion}

Among MSM in Congo, HIV prevalence is high as a result of high-risk sexual behavior. The results suggest that MSM constitute a priority population for AIDS programs in the Congo. Interventions should include preventive advice, condom supplies, HIV and STI testing and communication on the high risk of HIV transmission associated with condomless anal intercourse if a partner carries HIV and has an uncontrolled viral load.

\section{Author Contributions}

$\mathrm{NG}$ et $\mathrm{MB}$ designed the study and performed the statistical analysis. NG wrote a first draft of paper. AJA, RB, BA and JAN contributed to writing of the report. GO contributed to critical revision of the report. All authors contributed to reviewed and approved the final version.

\section{References}

[1] UNAIDS Global HIV \& AIDS statistics - 2020 fact sheet. [Internet]. [cité 15 nov 2020]. Disponible sur: https://www.unaids.org/en/resources/fact-sheet.

[2] UNAIDS Key population groups. 2017. [Internet]. [cité 15 nov 2020]. Disponible sur: https://www.unaids.org/en/topic/key-populations.

[3] Gallardo L T, Castro D R and Le Gal J-M 2012 Lutte contre le sida et homoxualité en Afrique francophone: une étude comparative. [Internet]. [cité 14 nov 2020]. Disponible sur: https://www.researchgate.net/publication/317667228 Lutte c ontre_le_VIH_et_homosexualites_en_Afrique_francophone Une_etude comparative/link/594826 cf0f7e9b1 19 b232176/do wnload/.

[4] Desenclos J-C, Dabis F and Semaille C 2013 Global HIV epidemiology: specific patterns of the epidemic in the North and South Virol. Montrouge Fr. 17 132-44.

[5] Kitara D L and Aloyo J 2012 HIV/AIDS Stigmatization, the Reason for Poor Access to HIV Counseling and Testing (HCT) Among the Youths in Gulu (Uganda) Afr. J. Infect. Dis. 6 12-20.

[6] Skinner D and Mfecane S 2004 Stigma, discrimination and the implications for people living with HIV/AIDS in South Africa SAHARA J J. Soc. Asp. HIVAIDS Res. Alliance 1 157-64.

[7] Baral S, Trapence G, Motimedi F, Umar E, Iipinge S, Dausab $\mathrm{F}$ and Beyrer C 2009 HIV prevalence, risks for HIV infection, and human rights among men who have sex with men (MSM) in Malawi, Namibia, and Botswana PloS One 4 e4997. 
[8] Wirtz A L, Jumbe V, Trapence G, Kamba D, Umar E, Ketende S, Berry M, Strömdahl S, Beyrer C and Baral S D 2013 HIV among men who have sex with men in Malawi: elucidating HIV prevalence and correlates of infection to inform HIV prevention J. Int. AIDS Soc. 16 Suppl 318742.

[9] Wade A S, Kane C T, Diallo P A N, Diop A K, Gueye K, Mboup S, Ndoye I and Lagarde E 2005 HIV infection and sexually transmitted infections among men who have sex with men in Senegal AIDS Lond. Engl. 19 2133-40.

[10] Hessou S P H, Glele-Ahanhanzo Y, Adekpedjou R, Ahoussinou C, Djade C D, Biaou A, Johnson C R, Boko M and Alary M 2020 HIV incidence and risk contributing factors among men who have sex with men in Benin: A prospective cohort study PloS One 15 e0233624.

[11] CNSEE, CNLS, ICF MACRO Congo, Rep. - Enquête de Séroprévalence et sur les Indicateurs du Sida du Congo 2009.

[12] CNLS-Congo 2012 Enquête comportementale couplée à la sérologie VIH chez les hommes ayant des rapports sexuels avec les hommes, les professionnelles de sexe, les consommateurs de drogues injectables et les détenus en république du Congo.

[13] Heckathorn D D 1997 Respondent-Driven Sampling: A New Approach to the Study of Hidden Populations Soc. Probl. 44 174-99.

[14] Salganik M J and Heckathorn D D 2004 Sampling and Estimation in Hidden Populations Using Respondent-Driven Sampling Sociol. Methodol. 34 193-239.

[15] Niama $F$ R, Loukabou Bongolo $N$ C, Mayengue $P$ I, Mboussou F F, Kombo Bayonne E S, Kouckodila Nzingoula F M, Dossou-Yovo L R, Louzolo I, Etoka-Beka M K, Lanzy A, Yameogo I, Louvouezo D, Kobawila S C, Puruhence M-F and Parra H J 2017 A study on HIV, Syphilis, and Hepatitis B and $\mathrm{C}$ virus infections among female sex workers in the Republic of Congo Arch. Public Health 7521.

[16] Beyrer C, Trapence G, Motimedi F, Umar E, Iipinge S, Dausab F, et al. Bisexual concurrency, bisexual partnerships, and HIV among Southern African men who have sex with men. Sex Transm Infect. août 2010; 86 (4): 323-7.

[17] Park JN, Papworth E, Kassegne S, Moukam L, Billong SC, Macauley I, et al. HIV prevalence and factors associated with HIV infection among men who have sex with men in Cameroon. J Int AIDS Soc. 2 déc 2013; 16 Suppl 3: 18752.

[18] Sandfort TGM, Dominguez K, Kayange N, Ogendo A, Panchia R, Chen YQ, et al. HIV testing and the HIV care continuum among sub-Saharan African men who have sex with men and transgender women screened for participation in HPTN 075. PloS One. 2019; 14 (5): e0217501.

[19] Twahirwa Rwema JO, Lyons CE, Herbst S, Liestman B, Nyombayire J, Ketende S, et al. HIV infection and engagement in HIV care cascade among men who have sex with men and transgender women in Kigali, Rwanda: a cross-sectional study. J Int AIDS Soc. oct 2020; 23 Suppl 6: e25604.

[20] Keshinro B, Crowell TA, Nowak RG, Adebajo S, Peel S, Gaydos CA, et al. High prevalence of HIV, chlamydia and gonorrhoea among men who have sex with men and transgender women attending trusted community centres in Abuja and Lagos, Nigeria. J Int AIDS Soc. 2016; 19 (1): 21270 .

[21] Kayode BO, Mitchell A, Ndembi N, Kokogho A, Ramadhani HO, Adebajo S, et al. Retention of a cohort of men who have sex with men and transgender women at risk for and living with HIV in Abuja and Lagos, Nigeria: a longitudinal analysis. J Int AIDS Soc. oct 2020; 23 Suppl 6: e25592.

[22] ONUSIDA 90-90-90: traitement pour tous. [Internet]. [cité 11 nov 2020]. Disponible sur: https://www.unaids.org/fr/resources/909090.

[23] Doyle A M, Mavedzenge S N, Plummer M L and Ross D A 2012 The sexual behaviour of adolescents in sub-Saharan Africa: patterns and trends from national surveys Trop. Med. Int. Health TM IH 17 796-807.

[24] Rizvi F, Williams J and Hoban E 2019 Factors Influencing Unintended Pregnancies amongst Adolescent Girls and Young Women in Cambodia Int. J. Environ. Res. Public. Health 16.

[25] Shah P S, Balkhair T, Ohlsson A, Beyene J, Scott F and Frick C 2011 Intention to become pregnant and low birth weight and preterm birth: a systematic review Matern. Child Health J. 15 205-16.

[26] Baral S, Trapence G, F Motimedi, Umar E, S Iipinge, Dausab F, et al. 2009 HIV prevalence, risks for HIV infection, and human rights among men who have sex with men (MSM) in Malawi, Namibia, and Botswana. PLoS ONE 4 (3): e4997.

[27] Guo W, Li Y, Zhou N, Wu G H, Chang W H, Huan X P, Hui S, Tong X, Guo Y, Yu M H, Lu R R, Ouyang L, Dong L F, Li H, Li J J, Liu X Y, Liu Y L, Luo C, Wei X L, Huang X D and Cui Y 2018 [Risk factors related to HIV new infections among men who have sex with men in a cohort study] Zhonghua Liu Xing Bing Xue Za Zhi Zhonghua Liuxingbingxue Zazhi 39 $16-20$.

[28] Hernandez I, Reina-Ortiz M, Johnson A, Rosas C, Sharma V, Teran S, Naik E, Salihu H M, Teran E and Izurieta R 2017 Risk Factors Associated With HIV Among Men Who Have Sex With Men (MSM) in Ecuador Am. J. Mens Health 11 1331-41.

[29] Boily M-C, Baggaley R F, Wang L, Masse B, White R G, Hayes R J and Alary M 2009 Heterosexual risk of HIV-1 infection per sexual act: systematic review and meta-analysis of observational studies Lancet Infect. Dis. 9 118-29.

[30] Baggaley R F, White R G and Boily M-C 2010 HIV transmission risk through anal intercourse: systematic review, meta-analysis and implications for HIV prevention Int. J. Epidemiol. 39 1048-63.

[31] Gile K J and Handcock M S 2010 Respondent-Driven Sampling: An Assessment of Current Methodology Sociol. Methodol. 40 285-327.

[32] Badowski G, Somera L P, Simsiman B, Lee H-R, Cassel K, Yamanaka A and Ren J 2017 The efficacy of respondent-driven sampling for the health assessment of minority populations Cancer Epidemiol. 50 214-20. 